\title{
Principais bactérias causadoras de sepse: sepse em unidade de terapia intensiva
}

\author{
Main sepsis-causing bacteria: sepsis in the intensive care unit \\ Principales bacterias causantes de sepsis: sepsis en la unidad de cuidados intensivos
}

Recebido: 28/10/2021 | Revisado: 07/11/2021 | Aceito: 08/11/2021 | Publicado: 13/11/2021

\author{
Edilvânia Brito Ferreira \\ ORCID: https://orcid.org/0000-0003-3607-7387 \\ Instituto Educacional Santa Catarina - Faculdade Guaraí, Brasil \\ E-mail: edilvaniabritoferreira@gmail.com \\ Maria Eduarda Franco Araújo \\ ORCID: https://orcid.org/0000-0001-6334-0705 \\ Instituto Educacional Santa Catarina - Faculdade Guaraí, Brasil \\ E-mail: meduardafrancoaraujo@gmail.com \\ Mara Régina Lucena Cabral \\ ORCID: https://orcid.org/0000-0003-2739-7231 \\ Instituto Educacional Santa Catarina - Faculdade Guaraí, Brasil \\ E-mail: mararegina.uft@gmail.com \\ Liberta Lamarta Favoritto Garcia Neres \\ ORCID: https://orcid.org/0000-0003-1327-605X \\ Instituto Educacional Santa Catarina - Faculdade Guaraí, Brasil \\ E-mail: liberta.neres@iescfag.edu.br
}

\begin{abstract}
Resumo
A sepse pode ser definida como uma resposta sistêmica a uma doença infecciosa específica, seja ela causada por bactérias, vírus, fungos ou protozoários. Sendo a principal causa de morte em unidades de terapia intensiva (UTI). O estudo objetivou identificar os fatores clínicos e os fatores relacionados aos óbitos em pacientes que se encontram internados com sepse na Unidade de Terapia Intensiva, envolvendo pacientes com diagnóstico de COVID19 e pacientes que realizaram procedimentos invasivos com o uso de cateter. Trouxe a compreensão do quanto é importante o diagnóstico precoce para diminuição da mortalidade em pacientes internados em UTI e o manejo correto com antimicrobianos e fatores de risco para o agravamento da sepse. Faz se necessário que os profissionais da saúde estejam atentos a todos os sinais e sintomas que antecedem o quadro grave de sepse. $\mathrm{O}$ estudo está baseado em artigos publicados entre 2015 e 2021 encontrados nas plataformas digitas LILACS (Literatura Latino Americana em Ciências de Saúde), GOOGLE ACADÊMICO e na biblioteca eletrônica SciElo (Scientific Eletronic Library Online).
\end{abstract}

Palavras-chave: Sepse; Unidade de Terapia Intensiva; Complicação infecciosa; Infecção hospitalar.

\begin{abstract}
Sepsis can be defined as a systemic response to a specific infectious disease, whether caused by bacteria, viruses, fungi or protozoa. Being the leading cause of death in intensive care units (ICU). The study aimed to identify the clinical factors and factors related to death in patients hospitalized with sepsis in the Intensive Care Unit, involving patients diagnosed with COVID19 and patients who underwent invasive procedures using a catheter. It brought the understanding of how important early diagnosis is to reduce mortality in patients admitted to the ICU and the correct management with antimicrobials and risk factors for the worsening of sepsis. It is necessary that health professionals are aware of all signs and symptoms that precede the severe condition of sepsis. The study is based on articles published between 2015 and 2021 found on digital platforms LILACS (Latin American Literature in Science of Health), ACADEMIC GOOGLE and the SciElo electronic library (Scientific Electronic Library Online).
\end{abstract}

Keywords: Sepsis; Intensive Care Unit; Infectious complication; Nosocomial infection.

\section{Resumen}

La sepsis se puede definir como una respuesta sistémica a una enfermedad infecciosa específica, ya sea causada por bacterias, virus, hongos o protozoos. Siendo la principal causa de muerte en unidades de cuidados intensivos (UCI). El estudio tuvo como objetivo identificar los factores clínicos y los factores relacionados con la muerte en pacientes hospitalizados por sepsis en la Unidad de Cuidados Intensivos, involucrando pacientes diagnosticados de COVID19 y pacientes sometidos a procedimientos invasivos mediante catéter. Trajo la comprensión de la importancia del diagnóstico precoz para reducir la mortalidad en los pacientes ingresados en la UCI y el correcto manejo con antimicrobianos y factores de riesgo para el agravamiento de la sepsis. Es necesario que los profesionales de la salud conozcan todos los signos y síntomas que preceden a la condición grave de sepsis. El estudio se basa en artículos publicados entre 2015 y 2021 encontrados en plataformas digitales LILACS (Literatura Latinoamericana en Ciencia 
de Health), ACADEMIC GOOGLE y la biblioteca electrónica SciElo (Scientific Electronic Library Online).

Palabras clave: Sepsis; Unidad de Cuidados Intensivos; Complicación infecciosa; Infección hospitalaria.

\section{Introdução}

A sepse pode ser definida como uma resposta sistêmica a uma determinada doença infecciosa, seja ela causada por bactérias, vírus, fungos ou protozoários (Costa, 2019). A sepse é causada pela resposta inflamatória sistêmica descontrolada de um indivíduo e é contagiosa. É causada quando a infecção piora, fazendo com que o corpo seja incapaz de controlá-la e afetando o sistema imunológico. Em resposta, o corpo causa mudanças na temperatura, pressão sanguínea, frequência cardíaca, contagem de glóbulos brancos e respiração (Santos,2019).

Apesar dos números reais serem desconhecidos e possam estar subestimados, estima-se que ocorram aproximadamente 60,2 milhões de casos anualmente em todo o mundo (Conselho, 2015). A Unidade de Terapia Intensiva possui os números aumentados para novos casos de sepse devido aos fatores como as morbidades preexistentes do paciente em estado crítico e de sua gravidade; ao longo período de internação; sobretudo em pacientes idosos; e a grande demanda de procedimentos invasivos (Vasconcelos,2019).

As manifestações clínicas da sepse abrangem aquelas relacionadas ao foco infeccioso em questão. A sepse se caracteriza pelo aparecimento de sinais da resposta inflamatória. O choque séptico é o de mais pronto diagnóstico, pois a hipotensão é facilmente evidente. Todos os esforços devem ser realizados para o diagnóstico precoce da sepse, quando a intervenção tem maior probabilidade de prevenir o óbito (Conselho, 2015).

O crescimento da resistência bacteriana vem contribuindo para o aumento de casos de sepse e parte desse crescimento é devido a manipulação dos pacientes pelos profissionais, causando riscos de contaminação, sendo que os principais patógenos são: bacilos gram-negativos: Klebsiella spp. e Pseudomonas aeruginosa e cocos gram-positivos, tendo o Esthaphylococcus como o principal causador de sepse. (Machado, 2017). Embora o Staphylococcus aureus seja um dos patógenos mais relacionados à bacteremia, está relacionado ao uso de cateteres intravenosos (Conselho, 2015).

Diante de inúmeras possibilidades a sepse pode se tornar a terapia mais complexa, diminuindo assim as possibilidades de reabilitação do paciente. O conhecimento dos fatores predisponentes, sinais clínicos, diagnóstico precoce e tratamento, constituem critérios de suma importância para lidar com a situação que exige urgência no tratamento, habilidade na assistência e observação rigorosa da evolução dos sinais e sintomas. (Machado, 2017).

Uma das áreas de formação, onde o profissional é habilitado e capacitado para dar o diagnóstico precoce resultando assim o tratamento eficaz é a biomedicina. O mesmo, sendo comprometido com sua incumbência torna-se um profissional adequado no desenvolvimento do diagnóstico da infecção. E por operar em campo de pesquisa, o biomédico trata cada diagnóstico como prova conclusiva de cada suspeita. Esta revisão bibliográfica tem como objetivo apresentar o desenvolvimento da sepse e seus níveis de complexidade até a sua forma mais grave retratando agressão de um ou diversos órgãos por microrganismos. O estudo retrata da sepse como um agravo responsável por um alto número de vítimas devido a diversos desencadeadores, como por exemplo os pacientes que se encaixam no perfil de imunodeprimidos.

\section{Materiais e Métodos}

Pesquisa do tipo revisão bibliográfica em que foi realizado um levantamento bibliográfico, para a escolha dos artigos que compõem o referencial teórico, foi realizada uma busca na base de dados LILACS (Literatura Latino Americana em Ciências de Saúde), GOOGLE ACADÊMICO e na biblioteca eletrônica SciElo (Scientific Eletronic Library Online). Foram estabelecidos como critérios de escolha artigos publicados no período de 2015 a 2021 , no idioma português e inglês. Na pesquisa foram incluídos artigos que responderam todos aos objetivos e hipóteses do trabalho. A busca resultou em oitenta e três artigos, 
dos quais, após serem analisados, título e objetivo, foram retirados sessenta e três, que não atenderam aos critérios da pesquisa, sendo selecionados vinte artigos, que abordavam o objetivo do estudo.

Figura 1: fluxograma de artigos.

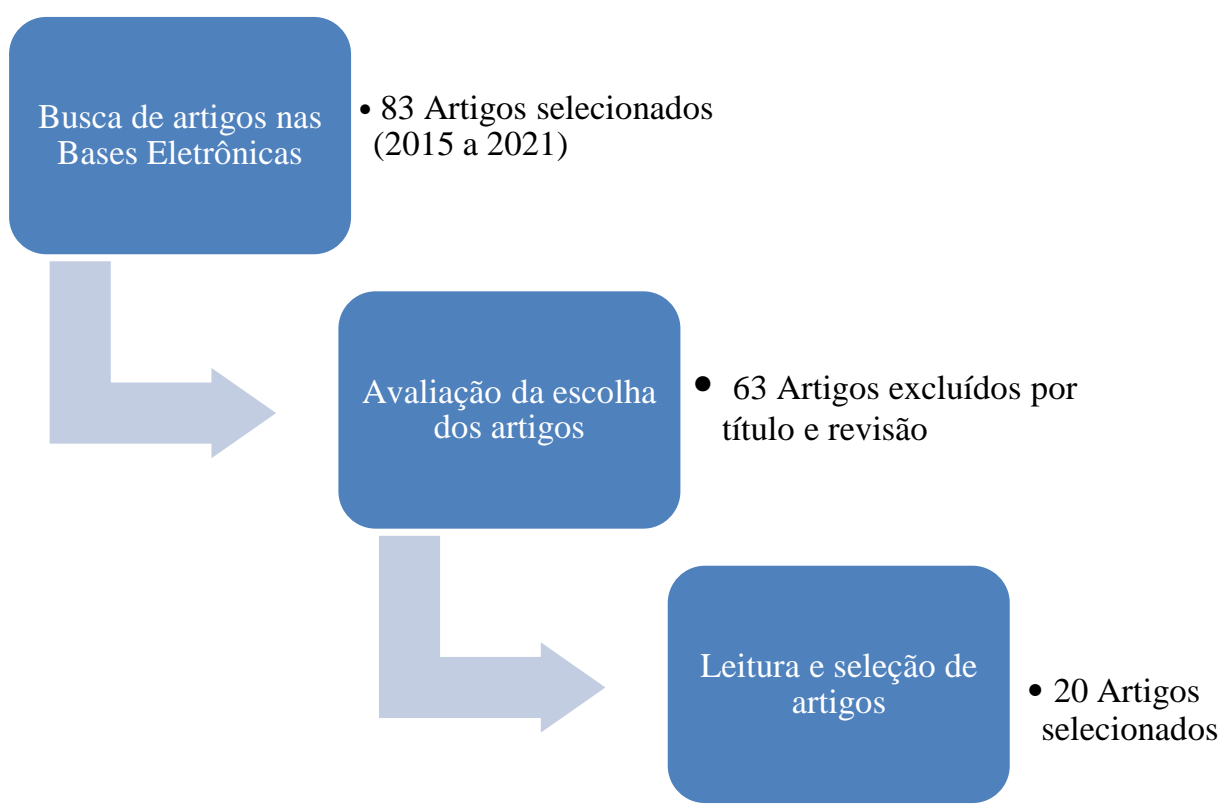

Fonte: autoria própria.

\section{Revisão de Literatura}

Diversos termos no decorrer da história foram desenvolvidos e aplicados ao conceito de sepse, principalmente por falta do conhecimento fundamental relacionado ao significado das condições clínicas específicas comuns em pacientes com sepse. A sepse é caracterizada por uma resposta imunológica e inflamatória sistêmica exacerbada, em resposta à uma infecção, levando a perda da hemostasia e disfunção de múltiplos órgãos e é constituída por uma série de anormalidades, causadas por um distúrbio da resposta inflamatória do paciente devido à infecção (Satriano, 2017).

A estimativa é de que nos últimos 30 anos a incidência de sepse cresceu 13,7\% ao ano. Diante dos dados coletados anualmente é considerado que 18 milhões de pacientes são acometidos por sepse e mais de 5 milhões chegam a óbito. De acordo com os dados epidemiológicos de sepse em Unidade de Terapia Intensiva (UTI) no Brasil, a incidência da do ença nesses departamentos é de $16,7 \%$. Devido a fatores como morbidade prévia e gravidade de pacientes criticamente enfermos, o departamento de terapia intensiva teve um aumento de casos de sepse; longa permanência hospitalar, especialmente em idosos; maior prevalência de desenvolvimento de resistência microbiana e um grande número de procedimentos invasivos (Vasconcelos,2019).

Com o avanço da ciência, é possível deliberar métodos fisiológicos, patológicos e bioquímicos que determinam se o paciente vem apresentando um quadro de sepsemia. A ausência de tratamentos adequados diante do quadro de infeções, está correlacionado diretamente a ascensão das taxas de ocorrência e mortalidade por sepse (Satriano, 2017). Na atualidade os números apontam taxas elevadas de mortalidade por sepse nacionalmente, tendo como um dos principais locais de acometimento os hospitais públicos (Nascimento, 2018).

Devido ao aumento da mortalidade por sepse, o diagnóstico precoce da infecção é extremamente importante. No entanto, isso geralmente não é possível porque as manifestações clínicas são confundidas com vírus ou bactérias inespecíficas ou outros processos não infecciosos. Estudos têm demonstrado que a detecção rápida da sepse está relacionada ao tratamento 
adequado e traz inúmeros resultados benéficos aos pacientes. $\mathrm{O}$ uso de antimicrobianos específicos na primeira hora após o diagnóstico pode ajudar muito os pacientes a obterem resultados favoráveis (Nascimento, 2018) (R Beardsley, 2016). A síndrome é caracterizada pela presença de um mecanismo inflamatório, sendo diagnosticadas alterações no sistema celular e circulatório, como vasodilatação e aumento da permeabilidade capilar, levando a hipovolemia e hipotensão, diminuição da densidade capilar e coagulação intravascular difusa, que afeta a Redução de oxigênio dos tecidos, levando ao aumento do metabolismo anaeróbio e acidemia hiper lática (Nascimento, 2018).

As bactérias são microrganismos unicelulares e procarióticos que não possuem clorofila e podem possuir tanto ácido desoxirribonucleico (DNA), quanto ácido ribonucleico (RNA), envoltos pela membrana plasmática que encontra - se interna a parede celular, uma estrutura que por servir de barreira seletiva entre o citoplasma e o ambiente interior da célula, é essencial para todas as células elucidado (Santos,2019).

Esses microrganismos chegam ao hospedeiro através de uma variedade de vias, como o trato respiratório, trato gastrointestinal e trato urogenital, ou através de membranas mucosas e pele lesada (Ferreira, 2018). Entre eles, diferentes níveis de virulência de defesa do hospedeiro são listados de acordo com o número de organismos e seus números, porque quando entram nos tecidos, sua capacidade de eliminar ou lutar contra os organismos dependerá da resposta imunológica aos antígenos microbianos. As bactérias possuem uma estrutura que as distingue e classifica como Gram-positivas e Gramnegativas. A parede das bactérias gram-positivas é basicamente composta por uma camada de peptidoglicano imediatamente fora da membrana plasmática, enquanto as bactérias gram-negativas possuem uma camada de lipopolissacarídeo além do peptidoglicano, que é o principal fator de virulência das bactérias Gram Negativas, para determinar o biológico efeito que levam à amplificação da inflamação e infecção (Santos, 2019).

Em pacientes de UTI, o foco de infecção de procedimentos invasivos é relevante com bactérias resistentes a vários medicamentos, como Staphylococcus aureus resistente à meticilina, tendo necessidade de antibioticoterapia de amplo espectro. O tipo de bactéria que causa a sepse está intimamente relacionado ao local da lesão. O Staphylococcus epidermidis causa infecções hospitalares relacionadas ao cateter. A flora adquirida no ambiente hospitalar tende a um padrão de resistência aos antibióticos que varia de instituição e sabe-se que é um meio detectar esses padrões de resistência. (Betina, 2019).

O cateter vem sendo considerado como uma das formas de acesso para os microrganismos, favorecendo a obtenção da infecção. Compreender a relação entre os cateteres, pacientes e microrganismos é essencial para uma compreensão abrangente da patogênese das infecções relacionadas ao cateter. As consequências da infecção por chegam de infeções locais à infecções sistêmicas, nomeadas sepse, uma série de complicações que podem levar o paciente ao óbito (Ribeiro, 2019).

A seriedade das infecções por cateter torna de grande importância a identificação das características e da prevalência dos microrganismos responsáveis pela infecção. De acordo com estudos os microrganismos mais encontrados em biofilmes à cateteres são: Staphylococcus aureus e Staphylococcus coagulase negativo, seguidos de Pseudomonas aeruginosa, Acinetobacter baumannii e Klebsiella pneumoniae (Ribeiro, 2019).

Os cateteres são um dos principais dispositivos que causam infecções do sistema circulatório. Portanto, é necessário estar atento às medidas preventivas necessárias para o controle dessas infecções. As medidas a serem tomadas vão desde a escolha do cateter a ser utilizado até o manuseio e introdução do mesmo, fazendo uso correto de antissepsia e assepsi a (Ribeiro, 2019), (Vieira, 2020).

A preeminência dos microrganismos relacionados aos biofilmes está associada à microbiota do paciente. O S. aureus e Staphylococcus. Coagulase negativa fazem parte da flora normal da pele, podendo naturalmente contaminar os dispositivos médicos invasivos como os cateteres. A P. aeruginosa também pode fazer parte da flora normal, porém é considerada patógenos oportunistas (Vicente, 2021).

O diagnóstico de sepse continua sendo um grande desafio, pois se não for detectado precocemente, irá evoluir para 
choque séptico, falência de órgãos e até morte. Um dos motivos que torna o diagnóstico de sepse desafiador são as manifestações clínicas iniciais que podem não ser percebidas ou confundidas com outros processos não infecciosos. Além disso, indicadores laboratoriais indiretos, geralmente usados para confirmar o diagnóstico de sepse, individualmente, eles têm baixa sensibilidade e especificidade (Pires, 2020).

Quando há prognóstico de infecção por sepse são realizados os seguintes exames laboratoriais, como por exemplo; hemograma, exames bioquímicos e cultura de material biológico para identificar corretamente o patógeno e o melhor plano de tratamento com uso de antibióticos. As culturas de amostras do meio infeccioso, como uroculturas, amostras respiratórias e secreções de abscessos, são efetuadas para a identificação dos microrganismos causadores da infecção. Quando há suspeita de infecção da corrente sanguínea, pelo menos dois conjuntos de frascos de hemocultura devem ser coletados para identificar bactérias aeróbias e anaeróbias (Lima, 2019).

A comprovação do local da infecção, bem como a determinação dos patógenos e suas respectivas características de suscetibilidade, são essenciais para o correto tratamento antimicrobiano. No entanto, a principal desvantagem do treinamento é a demora na publicação dos resultados devido ao período prolongado de incubação, sendo necessários outros exames para auxiliar os profissionais a orientar o tratamento. O hemograma é um teste mais rápido do que a cultura e fornece parâmetros úteis para avaliação. Pacientes infectados podem apresentar alteração na contagem de leucócitos e, no caso de infecções agudas, presença de células imaturas da linhagem dos granulócitos no sangue periférico, o que pode diferenciá-los de pacientes saudáveis (Lima, 2019).

Em relação aos patógenos, indicando as principais bactérias gram-negativas associados à sepse e choque séptico estão Escherichia coli, Klebsiella pneumoniae e Pseudomonas aeruginosa, as principais bactérias gram-positivas são Staphylococcus aureus e Streptococcus pneumoniae. Há mais predominante na unidade de terapia intensiva do Brasil as bactérias Gramnegativas, como Pseudomonas aeruginosa e Acinetobacter baumannii. (Betina, 2019).

Para obter terapia antimicrobiana adequada, deve-se considerar a presença de hemoculturas positivas, sinais e sintomas de infecção, quando o paciente apresenta alguma outra infecção primária e quando algum tipo de equipamento médico invasivo é usado. Quando o paciente apresenta quadro clínico de infecção de corrente sanguínea (septicemia), deve-se levar em consideração que o resultado da hemocultura é negativo, o que pode acontecer quando são utilizados antibióticos anteriormente, o que dificulta o crescimento e a identificação dos microrganismos causadores da infecção. (Betina,2019).

O Staphylococcus aureus apresenta o maior índice de mortalidade causado por sua alta taxa de malignidade e por sua predominância no ambiente hospitalar. Compreendendo que os índices de contaminação por Staphylococcus aureus são significativos, chegando ao valor de 40 a $80 \%$, tornando se de grande importância o reconhecimento a prevalência do patógeno nos pacientes internados nas Unidades de Terapia Intensiva (Martins,2016).

Os S. aureus codificam as enzimas nomeadas proteínas ligadoras de penicilina (PBPs) que são responsáveis pela a sintetização da parede celular bacteriana e constituição dos alvos dos antibióticos $\beta$-lactâmicos. A resistência do $S$. aureus à meticilina ou oxacilina (ORSA/MRSA) e devido a obtenção do gene mecA que codifica PBPs alteradas denominadas de PBP2a ou PBP2', que tem combinação reduzida a meticilina ou oxacilina, e a todos os antibióticos $\beta$-lactâmicos, apesar de o fenótipo MRSA seja abundantemente disseminado, acontecem de amostras que apresentam sensibilidade a estes antimicrobianos, que são denominados de MSSA S. aureus sensíveis a meticilina (Cunha, 2017.

Os Staphylococcus são bactérias caracterizadas por características morfológicas de cocos gram-positivos. Staphylococcus aureus é uma espécie que apresenta resultado positivo para coagulase, e sua infecção pode ser classificada como superficial (infecção que lesa a pele e tecidos subcutâneos, geralmente causada pela invasão direta da pele e muco) e profunda (devido a bacteremia por outra infecção superficial ou ocasionalmente por pneumonia por aspiração). (Betina, 2019). Embora o Staphylococcus aureus seja um dos patógenos mais relacionados à bacteremia, está relacionado ao uso de cateteres 
intravenosos (Conselho, 2015).

A Sepse foi diagnosticada em proporção significativa dos pacientes falecidos por COVID19 e em proporção dos sobreviventes internados em unidade de terapia intensiva (UTI). Esses resultados vêm da avaliação de indicadores em exames de pacientes que, ao serem detectadas alterações, indicavam falência de um órgão. Como exemplo, a redução da contagem de plaquetas; Alterações no marcador de função renal creatinina; e aumento no nível de dímero-D no sangue, fragmentos de proteínas associados ao processo de coagulação. Mesmo antes da infecção pelo coronavírus (SARSCoV2) levar a uma pandemia em que teve um grande impacto na saúde da população e na economia em todo o mundo, os primeiros casos de evolução para uma doença respiratória aguda ocorreram no final de dezembro em Wuhan, China, em 2019. Com base em novos casos notificados em vários países dos cinco continentes, a Organização Mundial da Saúde (OMS) logo declarou uma emergência de saúde pública de preocupação global devido à sua alta e sustentada transmissibilidade entre pessoas1-2 (Melquiades, 2020).

Os sinais e sintomas mais comuns atribuídos à síndrome clínica incluem febre, mialgia ou fadiga, tosse seca e dispneia, que podem ser acompanhados por linfopenia, anormalidades da coagulação sanguínea ou opacidades pulmonares em vidro fosco bilaterais na tomografia computadorizada de tórax, causando aumento rápido. no número de admissões em UTI para suporte artificial das funções orgânicas dos pacientes mais gravemente enfermos com síndrome respiratória aguda grave (SARS) (Melquiades, 2020).

Curiosamente, pacientes infectados com sintomas típicos de gripe, também pode desenvolver um quadro clínico de sepse, que é conhecido por ser caracterizado por uma teia fisiopatológica complicada definida pela presença de disfunção orgânica com risco de vida devido à resposta imune desregulada do organismo à infecção. No entanto, quando há progressão para choque séptico, acentuadas anormalidades circulatórias, celulares e metabólicas refletem o uso inadequado de oxigênio pelas células, o que pode aumentar drasticamente a mortalidade (Melquiades, 2020), (Malakovski, 2019).

Os pacientes da COVID19 que desenvolveram sepse ou choque séptico eram principalmente recém-nascidos, adultos e idosos. As características clínicas mais comuns para todos os grupos foram: aumento da frequência cardíaca, diminuição da saturação de oxigênio, dispneia, hipertermia, letargia e taquipneia. Levantamento da faixa etária de pacientes internados em enfermarias e na unidade de terapia intensiva com complicações do COVID19 constatou que a maior proporção de casos nas enfermarias era de pessoas com 1 a 69 anos e pacientes com complicações. cuidados intensivos, o maior grupo era de pessoas com idade entre 60 e 69 anos (Caetano, 2021).

Para verificar a gravidade dos pacientes hospitalizados, um dos sistemas de pontuação usados pela equipe de saúde é o escore qSOFA, que tem sido usado em alguns pacientes com o novo coronavírus na admissão para ver se o escore funciona como uma estratégia de classificação precoce de casos da doença apresentando sepse (Caetano, 2021).

Com base na premissa de que não há aspecto patognomônico da doença séptica, muitas vezes é difícil no ambiente clínico da unidade de terapia intensiva determinar se um paciente gravemente enfermo com sintomas respiratórios tem uma infecção viral ou bacteriana. As principais doenças virais (por exemplo, COVID19) subdiagnosticadas em pacientes com suspeita de sepse podem levar à disseminação de infecções respiratórias em hospitais, ao uso desnecessário de antibióticos e ao uso inadequado de antivirais em ambiente hospitalar. (Melquiades, 2020).

\section{Considerações Finais}

Este trabalho auxiliou na compreensão quanto a importância do diagnóstico precoce na diminuição da mortalidade dos pacientes das Unidades de Terapia Intensiva, fazendo uso da antibioticoterapia adequada. Portanto quando a infeção está em estado grave, geralmente causada por vírus (por exemplo, COVID19) ou bactérias, o sistema de defesa é ativado e acaba prejudicando suas funções vitais. Porém é possível dar o diagnóstico da infecção antes que o quadro se agrave e ocasione a morte. Dessa forma, é importante identificar os sinais clínicos de uma possível infecção generalizada, diminuindo as sequelas para o 
paciente. Desse modo considera-se que os profissionais da UTI precisam se qualificar com o atendimento prestado para diminuição das taxas de infecção por sepse.

Considerando as questões apresentadas nas publicações e as hipóteses levantadas, faz-se necessário cada vez mais a exploração deste assunto em revisões integrativas, pesquisas bibliográficas e pesquisas de campo, para despertar à população científica a importância da avaliação e controle de casos de infeções hospitalares e novas tecnologias aplicadas ao gerenciamento destes casos.

\section{Referências}

De Moura Pires, H. F., et al. Sepse em unidade de terapia intensiva em um hospital público:: estudo da prevalência, critérios diagnósticos, fatores de risco e mortalidade. Brazilian Journal of Development. Brasília, 2020. 19 p.

Brixner, B. Infecção da Corrente Sanguínea: epidemiologia e diagnóstico molecular. Santa Cruz do Sul, f. 82, 2019. 82 p. Monografia - Universidade de Santa Cruz do Sul. Universidade Santa Cruz do Sul, 2019.

Conselho Federal de Medicina - CFM; Instituto Latino-Americano para Estudos da Sepse (ILAS). Sepse: Um problema de saúde pública: Um problema de saúde pública. Instituto Latino-Americano para Estudos da Sepse (ILAS). Brasília, 2015.

Costa, C. J. Correlação do prognóstico de sepse com os agentes etiológicos em hospital de Maceió- AL. Centro Universitário Tiradentes. Alagoas, 2019. 3 p.

Costa, M. B. V. et al. Características epidemiológicas de pacientes com sepse em unidade de terapia intensiva. Revista de Epidemiologia e Controle de Infecção. Pedrinhas, Sobral, Ceará, Brasil., 2019. 7 p.

da Silva, M. I. C., et al. Diagnósticos de enfermagem em casos de COVID-19 com evolução clínica para sepse. Research, Society and Developmen. 2019.14 p.

de Sousa, D. M., et al. Infecção por staphylococcus aureus resistente em unidade de terapia intensiva: Revisão integrativa. Revista de Enfermagem . Recife, 2016.

Faria, R. V., et al. Infecção de corrente sanguínea relacionada a cateter venoso central: avaliação dos fatores de riscos. Brazilian Journal of Health Review. Curitiba, 2021. 19 p.

Inácio, E. Dos S. Prevalência de infecções por bactérias e fungos em sepse na uti do hospital João Paulo II em Porto Velho-RO no período de 2017 a 2018. Ariquemes- RO, 2019.19 p

Malakovski, H., \& Kramer, K. Perfil clínico epidemiológico dos casos suspeitos de sepse e choque séptico em pronto socorro e unidade de internação hospitalar. Universidade Ferderal da Fronteira Sul. UFFS. Chapéco, 2019.22p.

Martins, M. V., et al. Fatores de riscos que contribuem para sepse relacionada ao cateter venoso central em unidades de terapia intensiva. razilianJournal of Development. Curitiba, 2020. 19 p.

Moura, L. F. Óbitos por septicemia no Brasil. Escola Bahiana de Medicina e Saúde Publica. Salvador, 2018.13 p.

Neto, J. M. R., et al. Diagnósticos/Resultados e intervenções de enfermagem para pacientes graves acometidos por covid-19 e sepse. . Texto \& Contexto Enfermagem. 2020. 17 p.

Pereira, A. L. Da C., et al. Vigilância e epidemiologia de infecções hospitalares causadas por Staphylococcus aureus em um hospital Universitário na cidade de Uberlândia-MG. Universidade Federal de Uberlândia Instituto de Biologia curso de ciências biológicas: Uberlândia-MG , 2017.

R Beardsley, J., Envolvimento do farmacêutico em uma iniciativa multidisciplinar para reduzir a mortalidade relacionada à sepse. National Library of Medicine. 2016

R. Lima Letícia. Contagem automatizada de granulócitos imaturos em pacientes de uma unidade de terapia intensiva com suspeita de infecção. Complexo Hospital de Clínicas da Universidade Federal do Paraná . Curitiba/ Paraná, 2019. 7 p.

Ribeiro, A. C., et al. Prevalência de microorganismos em infeccções e casos de SEPSE associadas ao cateter: uma revisão da literatura. Revista Ciencia \& Inovação. Campinas, 2019. 6 p.

Ribeiro, A. C., et al. Prevalência de microorganismos em infeccções e casos de SEPSE associadas ao cateter: uma revisão da literatura. Revista Ciencia \& Inovação. 2019.

Satriano, P. de M. Evolução das Diretrizes Internacionais de Definição e Identificação da Sepse e Choque Séptico. Brasília, f. 11, 2017. 22 p. Trabalho de Conclusão de Curso (Biomedicina) - Faculdade de Ciências da Educação e Saúde - FACES.

Zonta, F. N. S. Características epidemiológicas e clínicas da sepse em um hospital público do Paraná. Revista de Epidemiologia e Controle de Infecção . Paraná, 2018. 